\section{In Vivo Anti-estrogenic Effects of Menadione on Hepatic Estrogen-responsive Gene Expression in Male Medaka (Oryzias latipes)}

\author{
Akemi Yamaguchi, ${ }^{a, b}$ Shinya Kohra, ${ }^{b, c}$ \\ Hiroshi Ishibashi, ${ }^{d}$ Koji Arizono, ${ }^{d}$ \\ and Nobuaki Tominaga ${ }^{*}, a$
}

\begin{abstract}
${ }^{a}$ Department of Chemical and Biological Engineering, Ariake National College of Technology, 150 Higashihagio-machi, Omuta, Fukuoka 836-8585, Japan, ${ }^{b}$ Graduate School of Science and Technology, Nagasaki University, ${ }^{c}$ Faculty of Environmental Studies, Nagasaki University, 1-14 Bunkyo-machi, Nagasaki 852-8521, Japan, and ${ }^{d}$ Faculty of Environmental and Symbiotic Sciences, Prefectural University of Kumamoto, 3-110 Tsukide, Kumamoto 862-8502, Japan
\end{abstract}

(Received June 30, 2008; Accepted July 7, 2008; Published online July 9, 2008)

Menadione, a synthetic vitamin K3, exhibits antiestrogenic activity on in vitro assay. However, the in vivo anti-estrogenic effects of menadione have not been determined, while correlations between biological effects and structural changes are unclear. Thus, we investigated the in vivo anti-estrogenic activity of menadione under fluorescent light and dark conditions. Suppression of the hepatic estrogen response genes vitellogenin1 (VTG1), VTG2 and estrogen receptor- $\alpha$ (ER- $\alpha$ ) was used as an index of antiestrogenic activity. Male medaka (Oryzias latipes) were treated with nominal concentrations of menadione in the presence or absence of $17 \beta$-estradiol (E2), and hepatic VTG1, VTG2 and ER- $\alpha$ mRNA levels were determined by quantitative real-time PCR. In the presence of $\mathrm{E} 2$ under dark conditions, expression of hepatic VTG2 and ER- $\alpha$ genes was suppressed by menadione treatment. On the other hand, menadione activity was lost under fluorescent light conditions. These results suggest that menadione has antiestrogenic activity in vivo, and that this activity is diminished under fluorescent light, probably due to a structural change in menadione.

\footnotetext{
*To whom correspondence should be addressed: Department of Chemical and Biological Engineering, Ariake National College of Technology, 150 Higashihagio-machi, Omuta, Fukuoka 836-8585, Japan. Tel.: +81-944-53-8747; Fax: +81-944-538747; E-mail: tominaga@ariake-nct.ac.jp
}

Key words — menadione, anti-estrogenic, Oryzias latipes, in vivo

\section{INTRODUCTION}

Since endocrine-disrupting chemicals (EDCs) have been discovered, numerous studies on the hormone agonistic or antagonistic effects of these EDCs have been performed. ${ }^{1,2)}$ Vitellogenin (VTG), an estrogen-inducible phosphoprotein and complex precursor protein in egg yolk, is a useful biomarker for evaluating the (anti)estrogenic potential of certain EDCs. ${ }^{3)}$ Estrogenic compounds, including natural estrogens, regulate expression levels of the estrogen-responsive VTG gene by binding to a specific estrogen receptor (ER). Our previous studies have demonstrated the short-term effects of estrogenic compounds, such as E2, nonylphenol, bisphenol A and fluorotelomer alcohols, on the expression of estrogen-responsive genes, such as VTG and ER, in male medaka. ${ }^{4,5)}$

Menadione (2-methyl-1,4-naphthoquinone) is a synthetic vitamin $\mathrm{K} 3$. Vitamin $\mathrm{K}$ is reported to essential for blood coagulation and bone metabolism in vertebrates. ${ }^{6)}$ Menadione has been used extensively in the research of oxidant stress in mammalian hepatic cells. In hepatocyte systems, menadione reportedly increases consumption of molecular oxygen and production of superoxide radical anions, depletion of glutathione pools, and oxidation of protein sulfhydryl groups. ${ }^{7,8)}$ Menadione has also been shown to induce single-strand (ss) and double-strand (ds) DNA breaks in human MCF-7 cells, and to possess significant anticancer activity in vivo and in vitro. ${ }^{9)}$ In addition, menadione is toxic in invertebrates; Kim et al. assessed the genotoxicity of menadione in grass shrimp (Palaemonetes pugio) embryos using single cell gel electrophoresis, and reported that menadione induced DNA strand breaks during embryonic development. ${ }^{10)}$

Ship ballast water and sediment contain diverse invertebrate species, and the release of these species facilitates biological invasions that negatively affect the ecology of recipient ecosystems. ${ }^{11)}$ As menadione shows broad spectrum toxicity for invertebrates, is simple to transport and is safe to handle, Wright et al. investigated the toxicity of naphtoquinones, including menadione, against phytoplankton and bacteria, and examined their usage as biocides for ships ballast water treatment. ${ }^{12}$ Fur- 
thermore, Raikow et al. demonstrated that the toxicity of menadione is affected by sunlight in their assessment of the biocide potency of menadione against zooplankton and their resting eggs. ${ }^{13)}$

Mee et al. investigated the structural changes of menadione under sunlight conditions by gas chromatography and mass spectrometry. They suggested the possibility that menadione is converted to an oxide or epoxide on exposure to sunlight. ${ }^{14)}$ However, little is known about the biological effects of menadione, such as the correlation between the endocrine system and menadione molecular structure in vivo. Moreover, a previous study demonstrated the anti-estrogenic potential of menadione in an in vitro yeast two-hybrid assay. ${ }^{15)}$ They suggested that menadione inhibits the transcriptional activity of the E2 reporter gene, and directly binds to ER- $\alpha$ on competitive binding assay. However, there is no data on the anti-estrogenic potential of menadione in vivo.

The aim of this study is to investigate the in vivo anti-estrogenic activity of menadione in the presence or absence of $17 \beta$-estradiol (E2) on expression of hepatic VTG1, VTG2 and ER- $\alpha$ in male medaka under fluorescent light or dark conditions. The antiestrogenic potential of menadione has been compared with that of tamoxifen, an ER antagonist. Furthermore, we assess the variations in anti-estrogenic activity of menadione after fluorescent light treatment.

\section{MATERIALS AND METHODS}

Test Chemicals - Menadione (purity $>98.5 \%$, Wako Pure Chemical Industries, Ltd., Osaka, Japan), E2 (purity > 98\%, Sigma, St. Louis, MO, U.S.A.), and tamoxifen ([Z]-1-[p-dimethylaminoethoxyphenyl]-1,2-diphenyl-1-butene, purity > 99\%, Sigma), were used in this study. Reagents were dissolved in dimethyl sulfoxide (DMSO, purity $>99 \%$, Wako Pure Chemical Industries) for preparation of test solutions. Menadione stock solution was stored under dark conditions.

Chemical Exposure Design-d-rR strain medaka were kept for several years in glass tanks at $25 \pm 1^{\circ} \mathrm{C}$ under a $16: 8$ light: dark photoperiod and fed Altemia naupli once daily. Male medaka (approximately 4 months after hatching) were exposed to test compounds as reported previously. ${ }^{4}$ )

In order to investigate the anti-estrogenic effects of menadione or tamoxifen (as a positive control), three male medaka were exposed to nominal concentrations of $0.1,1,10$ and $100 \mu \mathrm{M}$ menadione or 0.1 and $1 \mu \mathrm{M}$ tamoxifen in the presence or absence of $3.7 \mathrm{nM}$ E2 for $8 \mathrm{hr}$. These treatments were performed in $200-\mathrm{ml}$ glass beakers at $25 \pm 1{ }^{\circ} \mathrm{C}$ under light or dark conditions. In exposure experiments, the control group was only exposed to the solvent carrier $0.01 \%$ DMSO for $8 \mathrm{hr}$. None of the exposure groups, including controls, were fed during the exposure period. At the end of the exposure period, livers were collected, rapidly frozen in liquid nitrogen, and stored at $-80^{\circ} \mathrm{C}$ until analysis.

Quantitative Real-time PCR - Total RNA preparation and reverse transcription were performed as described previously. ${ }^{4)}$ Quantification of hepatic VTG1, VTG2, ER- $\alpha$ and $\beta$-actin mRNA was performed by real-time PCR using FullVelocity SYBR Green Master Mix (Stratagene, La Jolla, CA, U.S.A.) and STRATAGENE Mx3000P ${ }^{\mathrm{TM}}$ (Stratagene). The specific primers for estrogenresponsive and reference genes were as follows: VTG1 (DDBJ accession no. AB064320) forward, 5'-TGGAAAGGCTGATGGGGAAG-3'; reverse, 5'-AACTGCAGGCATGGTGAGCC-3'; VTG2 (AB074891) forward, 5'-GTCTTCAGGAGGTCTTCTTC-3'; reverse, 5'-GGTAGACAATGGTATCCGAC-3'; ER- $\alpha$ (AB033491) forward, 5' GTCAGTCGGGTTACTTGGCC-3'; reverse, $5^{\prime}$ CATCACCTTGTCCCAACCTG-3'; $\quad \beta$-actin (S74868) forward, 5'-AGACCACCTACAGCATC3'; reverse, 5'-TCTCCTTCTGCATTCTGTCT-3'. Reaction mixtures were incubated at $94^{\circ} \mathrm{C}$ for $5 \mathrm{~min}$, followed by $35 \mathrm{PCR}$ cycles at $94^{\circ} \mathrm{C}$ for $30 \mathrm{~s}$, $62^{\circ} \mathrm{C}$ for $30 \mathrm{~s}$, and $72^{\circ} \mathrm{C}$ for $1 \mathrm{~min}$. All experiments were performed in duplicate. Expression levels of VTG1, VTG2 and ER- $\alpha$ mRNA were normalized against those of $\beta$-actin mRNA. Statistical analysis for VTG1, VTG2 and ER- $\alpha$ mRNA expression was performed by one-way analysis of variance (ANOVA) using Excel NAG statistical analysis (Numerical Algorithms Group Ltd., Oxford, UK).

Spectrum Measurement of Menadione Exposed to Fluorescence Light — A 1-mM menadione solution $(200 \mathrm{ml})$ was prepared from menadione stock solution, and was left to stand under an $18-\mathrm{W}$ fluorescent light. Samples were collected every 0, 2, 8 and 12 days after exposure, and were stored at $4{ }^{\circ} \mathrm{C}$ under dark conditions. Each sample was subjected to measurement using a U-3000 spectrophotometer (Hitachi High-Technologies Co., Ltd., Tokyo, Japan). The absorptions at $260 \mathrm{~nm}$ (reflect menadion) and $230 \mathrm{~nm}$ (reflected the decomposed prod- 
uct) were measured. Then the rate of decomposition under this condition was estimated from alteration of absorbance ratio of $260 \mathrm{~nm} / 230 \mathrm{~nm}$.

\section{RESULTS}

\section{Effects of Tamoxifen on Expression of Estrogen- responsive Genes}

Zhang and $\mathrm{Hu}$ reported that $\beta$-actin was down regulated in the estrogenic chemical treated medaka liver. ${ }^{16)}$ However we used $\beta$-actin to normalize gene expression in this study, since statistically difference was not observed in each treatment group (data not shown).

Treatment with $1 \mu \mathrm{M}$ tamoxifen in the presence of $3.7 \mathrm{nM}$ E2 significantly suppressed the expression levels of VTG1 and ER- $\alpha$ mRNA in the livers of male medaka $(p<0.05)$ (Fig. 1A and 1C). Although the expression levels of hepatic VTG1 and ER- $\alpha$ were also suppressed by treatment with $0.1 \mu \mathrm{M}$ tamoxifen plus E2, no statistically significant differences were observed (Fig. 1A and 1C). In the presence of 3.7 nM E2, expression levels of hepatic VTG2 mRNA were significantly reduced in the
0.1 and $1 \mu \mathrm{M}$ tamoxifen treatment groups, as compared with E2 treatment alone $(p<0.05)$ (Fig. 1B).

\section{Effects of Menadione on Expression Levels of Estrogen-responsive Genes}

Expression levels of ER- $\alpha$ mRNA in the livers of male medaka exposed to 0.1 and $1 \mu \mathrm{M}$ menadione for $8 \mathrm{hr}$ were significantly lower when compared to controls $(p<0.05)$ (Fig. 1C). With regard to induction of hepatic VTG1 and VTG2 mRNA expression after exposure to 0.1 and $1 \mu \mathrm{M}$ menadione, no differences compared to the control group were seen (Fig. 1A and 1B). On the other hand, treatment with $1 \mu \mathrm{M}$ menadione in the presence of $3.7 \mathrm{nM}$ E2 distinctly suppressed expression levels of hepatic VTG2 and ER- $\alpha$ mRNA in males, similarly to tamoxifen treatment $(p<0.05)$ (Fig. 1B and 1C). In the presence of E2, induction of hepatic VTG1 mRNA was not suppressed by treatment with 0.1 or $1 \mu \mathrm{M}$ menadione (Fig. 1A). In both the 10 and $100 \mu \mathrm{M}$ menadione treatment groups in the presence or absence of E2, all test fish died within 30 min and four hr, respectively (data not shown).
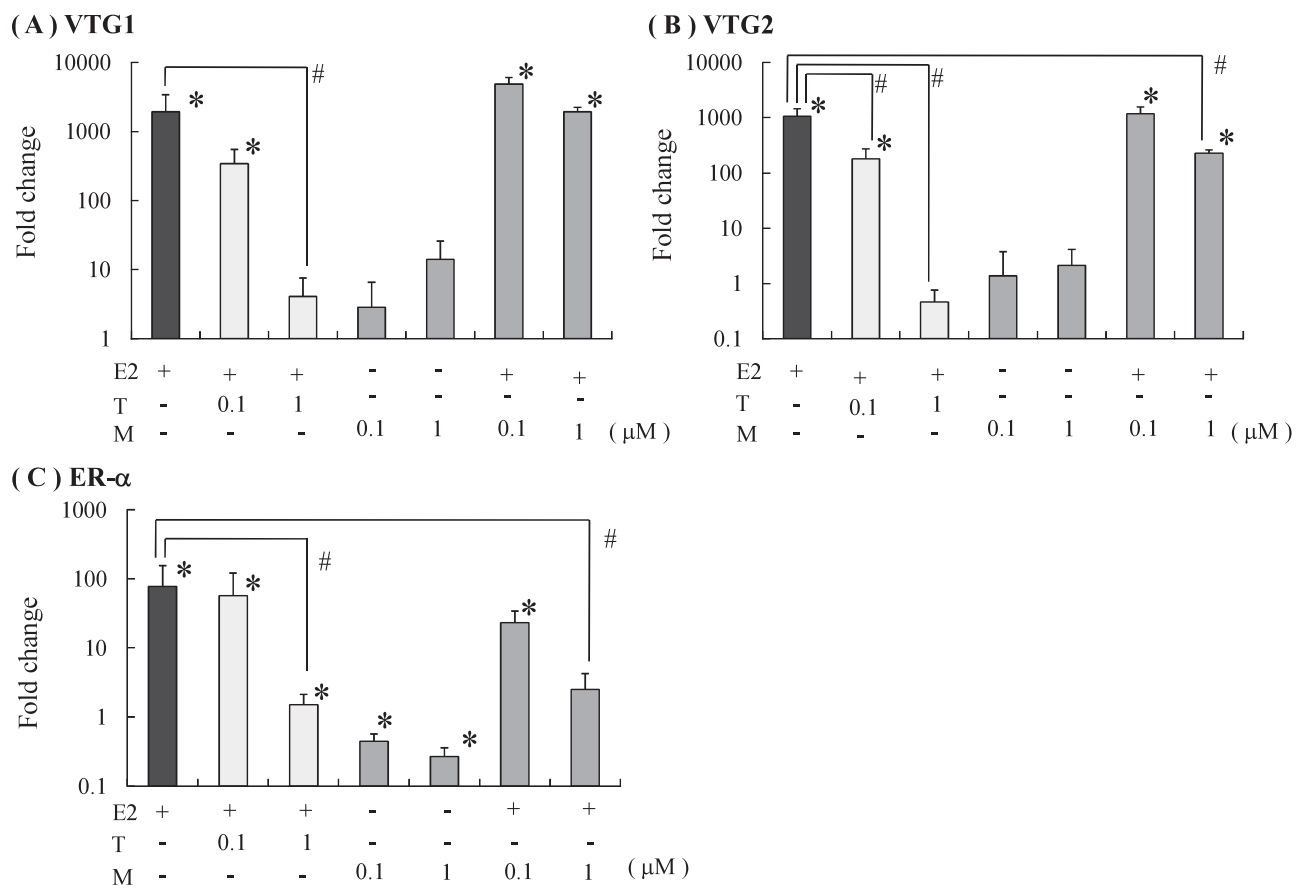

Fig. 1. Anti-estrogenic Effects of Tamoxifen and Menadione on VTG1 (A), VTG2 (B) and ER- $\alpha$ (C) mRNA Expression under Dark Condition in Male Medaka Liver

Three male medaka in each treatment groups were treated with $0.1,1 \mu \mathrm{M}$ menadione or tamoxifen in the presence or absence of E2 for $8 \mathrm{hr}$. Bars represent mean mRNA expression values \pm S.D. (relative to $\beta$-actin mRNA expression). M; menadione. T; tamoxifene. +; in treatment. Asterisk $\left(^{*}\right)$ denotes significant differences $v s$. control group. \# and bar that joins E2 and test chemical-treated groups indicate significant differences $v s$. E2 treatment group $(p<0.05)$. 
(A) VTG1

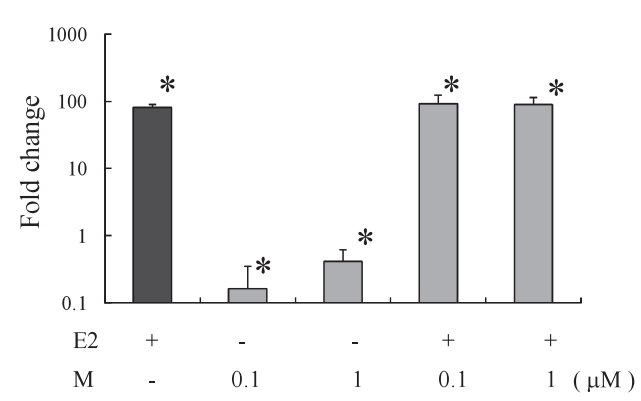

( C) ER- $\alpha$

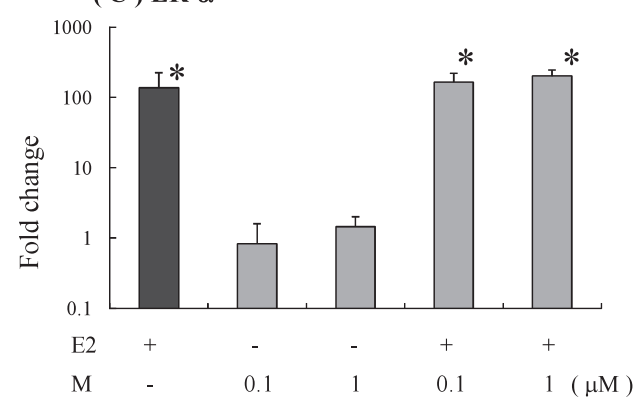

$(\mu \mathrm{M})$
( B ) VTG2

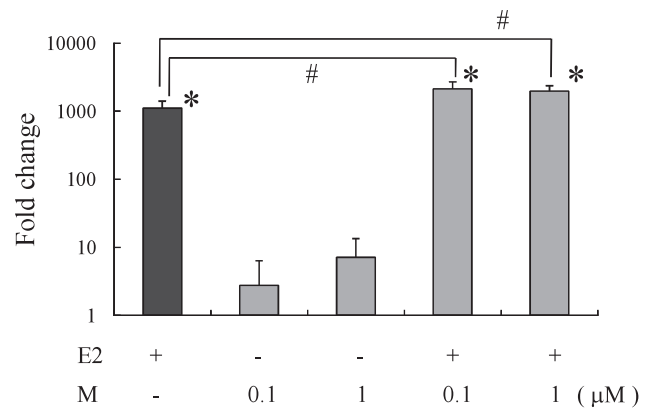

Fig. 2. Anti-estrogenic Effects of Menadione on VTG1 (A), VTG2 (B) and ER- $\alpha$ (C) mRNA Expression under Fluorescent Light Condition in Male Medaka Liver

Three male medaka in each treatment group were treated with $0.1,1 \mu \mathrm{M}$ menadione in the presence or absence of E2 for $8 \mathrm{hr}$. Data bars represent mean mRNA expression values \pm S.D. (relative to $\beta$-actin mRNA expression). M; menadione. +; in treatment. Asterisk $\left(^{*}\right)$ denotes significant differences $v s$. control group. \# and bar that joins E2 and test chemical-treated groups in the Figure indicate significant differences $v s$. E2 treatment group $(p<0.05)$.

\section{Effects of Fluorescent Light on Anti-estrogenic Potential of Menadione}

After exposing menadione to fluorescent light for $8 \mathrm{hr}$, the changes in the anti-estrogenic effects of menadione were investigated. In contrast to treatment under dark conditions, no significant changes in gene induction were observed in presence of $\mathrm{E} 2$ (Fig. 2A and C), despite the fact that VTG1 and ER$\alpha$ mRNA suppression was observed under dark conditions (Fig. 1A and C). In addition, VTG2 mRNA induction was slightly increased by menadione in the presence of E2 (Fig. 2B). Thus, under fluorescent light, menadione did not suppress E2 activity, and showed reduced anti-estrogenic activity.

\section{Changes in Menadione Spectrum after Fluores- cent Light Exposure}

The absorbance spectrum between $200 \mathrm{~nm}$ and $400 \mathrm{~nm}$ was measured. The spectrum was altered by fluorescent light immediately after the start of exposure, and was altered substantially after 2 days of treatment. Major peaks positioned between 250 and $270 \mathrm{~nm}$ were diminished, and new peaks appeared at $230 \mathrm{~nm}$ (Fig. 3). These changes were related to fluorescent light exposure time. Under this condition, the decomposition rate of menadione was estimated at $1.2 \mu \mathrm{mol} / \mathrm{h}$. Expose test solutions were $1 \mu \mathrm{mol} / \mathrm{l}$ and $0.1 \mu \mathrm{mol} / 1$, which contain $0.2 \mu \mathrm{mol} / 200 \mathrm{ml}$ and $0.02 \mu \mathrm{mol} / 200 \mathrm{ml}$ menadione respectively. Therefore 0.1 and $1 \mu \mathrm{M}$ menadione which used for in vivo treatment in this study are complete decomposed by fluorescent light within $8 \mathrm{hr}$.

\section{DISCUSSION}

Menadione is a synthetic vitamin K3, and is reportedly toxic to mammalian hepatic cells and invertebrates. ${ }^{7}{ }^{10)}$ Jung et al. studied the antiestrogenic activity of various chemical substances by yeast two-hybrid assay, reporter gene assay and competitive binding assay. They reported that menadione and other two chemicals (pentachlorophene and hexachlophene) bind to estrogen receptor competitively with E2, thus confirming anti-estrogenic activity in vitro. ${ }^{15)}$ However, the in vivo anti-estrogenic potency of menadione remains uncertain.

In this paper, we investigated the in vivo antiestrogenic action of menadione based on estrogen- 


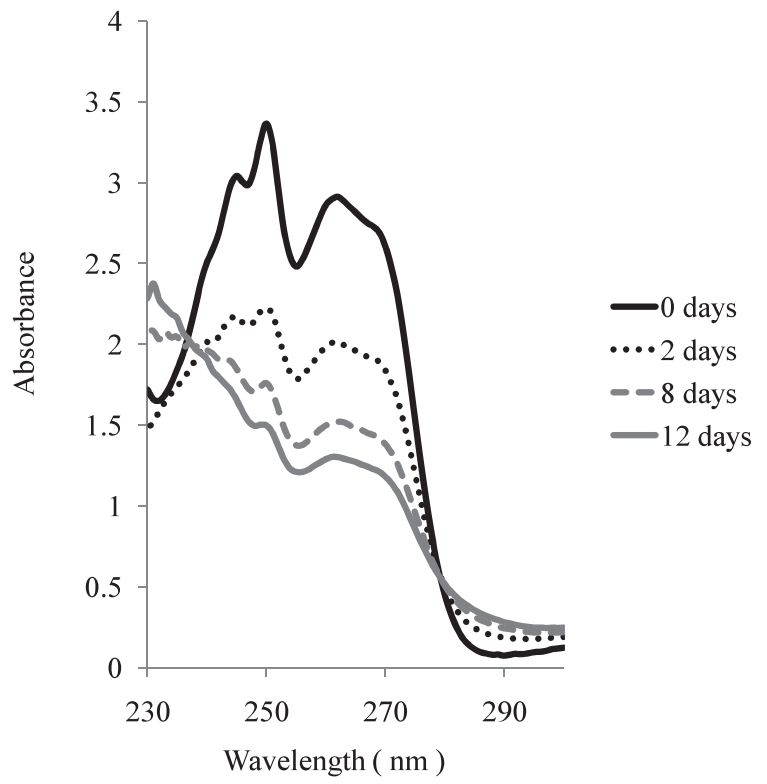

Fig. 3. Changes in Menadione Spectrum after Fluorescent Light Exposure

responsive gene (VTG 1,2 and ER- $\alpha$ ) expression in the liver of male medaka. Tamoxifen has been reported to be a partial agonist of E2 in male medaka, but it usually works as an antagonist in female and E2-treated male medaka. ${ }^{17)}$ Tamoxifen suppressed estrogen-responsive genes in the presence of E2. At $1 \mu \mathrm{M}$, tamoxifen showed particularly marked suppression when compared to $0.1 \mu \mathrm{M}$, and thus, tamoxifen exerts dose-dependent suppression. Sun et al. investigated plasma VTG concentrations in male and female medaka treated with various concentrations of tamoxifen for 21 days, and found that plasma VTG levels dose-dependently increased in male medaka. However, plasma VTG levels decreased in females treated with high levels of tamoxifen. ${ }^{17)}$ This suggests that tamoxifen shows partial agonistic activity due to competitive inhibition of E2, depending on its concentration in vivo. Taken together with our results, the data confirm that tamoxifen acts as a partial agonist in fish liver.

On the other hand, in male medaka treated with menadione, the induction pattern of estrogenresponsive genes was different from that with tamoxifen treatment. In the absence of E2, VTG1 and VTG2 mRNA was not induced, while ER- $\alpha$ mRNA levels in the liver were suppressed. In the presence of E2, however, menadione suppressed hepatic VTG2 mRNA and ER- $\alpha$ mRNA expression in livers in a dose-dependent manner. These results suggest that menadione shows anti-estrogenic activity in vivo. Although Jung et al. reported menadione binding activity to ER in vitro, ${ }^{15)}$ menadione did not induce estrogen-responsive genes in vivo. Thus, it is possible that menadione is a full E2 antagonist in vivo. Previously we showed VTG2 mRNA expressions lower than VTG 1 mRNA on non-treated male medaka liver and induction of VTG2 mRNA by E2 and estrogenic chemical treatment was more significant than that of VTG1 mRNA. ${ }^{4)}$ In this paper, we demonstrated that VTG2 mRNA was also more sensitive for anti-estrogenic effect than VTG1 mRNA.

Menadione was also found to lose antiestrogenic potency under fluorescent light. These results suggest that the anti-estrogenic potency of menadione is diminished by light irradiation. Vitamin $\mathrm{K}$ compounds, including menadione, are known to be affected by sunlight, irradiation and radioactivity. As menadione is toxic to invertebrates and is light sensitive, menadione is candidate biocide for ship ballast water, which contains numerous microorganisms. ${ }^{13}$ ) Raikow et al. investigated the changes in menadione toxicity under sunlight conditions, and found that toxicity to invertebrates is diminished by exposure to sunlight, thus suggesting that light exposure results in a structural change. Here, we also demonstrated that the anti-estrogenic activity is diminished, even after brief exposure to fluorescent light.

Mee et al. investigated the light decomposition of menadione by gas chromatograph mass spectrometry. They suggested that menadione is readily converted to an oxide or epoxide under sunlight. ${ }^{14)}$ It is likely that the same reaction occurred in our study. However, the molecular details of the structural changes are unclear. Further investigations into the molecular details and correlations with antiestrogenic activity in vivo are necessary.

In conclusion, we demonstrated that menadione shows anti-estrogenic activity in vivo, resulting suppression of hepatic estrogen-responsive genes, such as VTG2 and ER- $\alpha$, in male medaka, and that this activity is based on its molecular structure. This is the first report describing the in vivo anti-estrogenic activity of menadione. The relationship between anti-estrogenic potency and molecular structure of menadione will be investigated in the future, and this will help in understanding the structural relationship of anti-estrogenicity. 


\section{REFERENCES}

1) Colborn, T., Dumanoshi, D. and Myers, J. P. (1996) Our Stolen Future, Dutton, New York.

2) Colborn, T., von Saal, F. S. and Soto, A. M. (1993) Developmental effects of endocrinedisrupting chemicals in wildlife and humans. Environ. Health Perspect., 101, 378-384.

3) Sumpter, J. P. and Jobling, S. (1995) Vitellogenesis as a biomarker for estrogenic contamination of the aquatic environment. Environ. Health Perspect., 103, 173-178.

4) Yamaguchi, A., Ishibashi, H., Kohra, S., Arizono, K. and Tominaga, N. (2005) Short-term effects of endocrine-disrupting chemicals on the expression of estrogen-responsive genes in male medaka (Oryzias latipes). Aquat. Toxicol., 72, 239-249.

5) Ishibashi, H., Yamauchi, R., Matsuoka, M., Kim, J. W., Hirano, M., Yamaguchi, A., Tominaga, N. and Arizono, K. (2008) Fluorotelomer alcohols induce hepatic vitellogenin through activation of the estrogen receptor in male medaka (Oryzias latipes). Chemosphere, 71, 1853-1859.

6) Dahlbäck, B. (2000) Blood coagulation. Lancet, 355, 1627-1632.

7) Thor, H., Smith, M. T., Hartzell, P., Bellomo, G., Jewell, S. A. and Orrenius, S. (1982) The metabolism of menadione (2-methyl-1,4naphthoquinone) by isolated hepatocytes. A study of the implications of oxidative stress in intact cells. $J$. Biol. Chem., 257, 12419-12425.

8) Mirabelli, F., Salis, A., Perotti, M., Taddei, F., Bellomo, G. and Orrenius, S. (1988) Alterations of surface morphology caused by the metabolism of menadione in mammalian cells are associated with the oxidation of critical sulfhydryl groups in cytoskeletal proteins. Biochem. Pharmacol., 37, 34233427.

9) Nutter, L. M., Ngo, E. O., Fisher, G. R. and
Gutierrez, P. L. (1992) DNA strand scission and free radical production in menadione-treated cells. Correlation with cytotoxicity and role of NADPH quinone acceptor oxidoreductase. J. Biol. Chem., 267, 2474-2479.

10) Kim, G. B. and Lee, R. F. (2004) Effects of genotoxic compounds on DNA and development of early and late grass shrimp embryo stages. Mar. Environ. Res., 57, 329-338.

11) Drake, L. A., Doblin, M. A. and Dobbs, F. C. (2007) Potential microbial bioinvasions via ships' ballast water, sediment, and biofilm. Mar. Pollut. Bull., 55, 333-341.

12) Wright, D. A., Dawson, R., Cutler, S. J., Cutler, H. G., Orano-Dawson, C. E. and Graneli, E. (2007) Naphthoquinones as broad spectrum biocides for treatment of ship's ballast water: Toxicity to phytoplankton and bacteria. Water Res., 41, 1294-1302.

13) Raikow, D. F., Reid, D. F., Maynard, E. E. and Landrum, P. F. (2006) Sensitivity of aquatic invertebrate resting eggs to SeaKleen ${ }^{\circledR}$ (menadione): A test of potential ballast tank treatment options. Environ. Toxicol. Chem., 25, 552-559.

14) Mee, J. M. L., Brooks, C. C. and Yanagihara, K. H. (1975) Gas chromatographic-mass spectrometric investigation of the photo-epoxidation of vitamin $\mathrm{K} 3$. J. Chromatogr. A., 110, 178-181.

15) Jung, J., Ishida, K. and Nishihara, T. (2004) Antiestrogenic activity of fifty chemicals evaluated by in vitro assays. Life Sci., 74, 3065-3074.

16) Zhang, Z. and Hu, J. (2007) Development and validation of endogenous reference genes for expression profiling of medaka (Oryzias latipes) exposed to endocrine disrupting chemicals by quantitative realtime RT-PCR. Toxicol. Sci., 95, 356-368.

17) Sun, L., Zha, J., Spear, P. A. and Wang, Z. (2007) Tamoxifen effects on the early life stages and reproduction of Japanese medaka (Oryzias latipes). Environ. Toxicol. Pharmacol., 24, 23-29. 